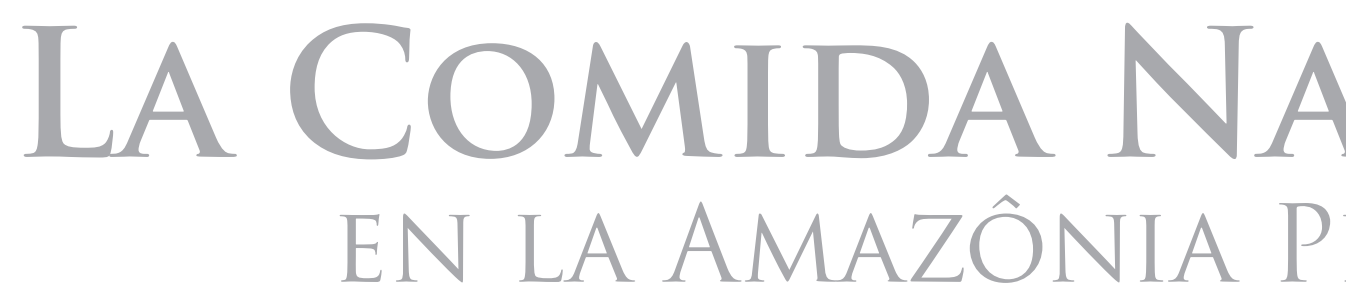




\section{LA COMIDA NATIVA EN LA AMAZONÍA PERUANA}

D A N I E L M R A E S C H O A N O 


\title{
Resumen
}

Desde tiempos pasados, la comida en las culturas prehispánicas de la Amazonía peruana es el resultado de la adaptación del hombre a su medio ambiente, en tal razón que en la selva siempre fue importante el consumo de carne de monte, pescado de río, con alto contenido de proteínas y vegetales como la yuca, maíz, maní, frijoles y los plátanos del huerto con alto contenido de carbohidratos, a la cual se le agregaba la infaltable bebida de masato. La evidencia arqueológica de los alimentos y su preparación no se han encontrado, sólo se han rescatado algunos instrumentos u objetos, y formas de las vajillas de comida, las cuales son presentados aquí para comprender el significado social antes que hablar de recetas culinarias. Así mismo los arqueólogos han planteado el debate sobre la existencia de una relación entre la agricultura que tiene que ver con la alimentación, el sedentarismo y el desarrollo de sociedades complejas. La información de la etnohistoria nos habla de pueblos muy grandes con mucha comida; en las referencias etnográficas encontramos el mito de origen del juego y los alimentos y actualmente en los grupos nativos existe una riqueza culinaria que es el resultado de este largo proceso que se inicia con la agricultura y el sedentarismo y la posterior influencia andino-quechua y occidental en la alimentación.

Palabras clave: Alimentación, adaptación, Amazonía peruana.

\begin{abstract}
In Pre-Columbian cultures of Amazonia, since ancient times, food is the result of humans' adaptation to their immediate environment. In the tropical Forest, the consumption of game and fish, for protein, and vegetables, such as manioc, maize, beans, and bananas, for calories (adding here fermented manioc beverages) were always critical. Archaeological evidence for meals and their preparation was not found; only tools, vessels, and objects were found, from which we can understand the social meaning of food, instead of talking about recipes. Even though, archaeologists have discussed the existence of a relationship between agriculture, which has to do with diet, sedentarism, and the development of complex societies. Ethnohistorical information tells us about large societies, with plenty of food; in ethnographical references, we find myths of origin for both the play and the food, and currently, amidst native peoples there is a culinary richness that is the result of this extensive process that began with
\end{abstract}


agriculture and sedestarism, and the ulterior influence AndeanQuechuan in the diet.

Keywords: Diet, adaptation, Peruvian Amazon.

\section{Resumo}

Desde tempos passados, a comida nas culturas pré-hispânicas da Amazonia peruana é o resultado da adaptação do homem a seu meio ambiente, de maneira que na floresta sempre foi importante o consumo de carne e peixe, com alto conteúdo de proteínas, e vegetais como a mandioca, o milho, o feijão e as bananas, com alto conteúdo de carboidratos, ao qual se agregava a bebida fermentada de mandioca. A evidência arqueológica dos alimentos e sua preparação não foi encontrada; somente foram resgatados alguns instrumentos ou objetos, e formas das vasilhas de comida, as quais são apresentadas aqui para que se compreenda o significado social, em vez de falarmos de de receitas culinárias. Assim mesmo, os arqueólogos têm colocado o debate sobre a existência de uma relação entre a agricultura, que tem a ver com a alimentação, o sedentarismo e o desenvolvimento de sociedades complexas. A informação da etnohistória nos fala de povos muito numerosos, com muita comida; nas referências etnográficas encontramos o mito de origem do jogo e dos alimentos e atualmente nos grupos nativos existe uma riqueza culinária que é o resultado desse extenso processo que se inicia com a agricultura e o sedentarismo e a posterior influência andino-quechua e ocidental na alimentação.

Palavras-chave: Alimentação, adaptação, Amazônia peruana. 


\section{INTRODUCCIÓN}

Una de las fortalezas más importantes del Perú, para el desarrollo del turismo, es sin lugar a dudas la gastronomía tan diversa en sus tres regiones naturales; sin embargo este atractivo de la región selvática es poco conocida, por falta de apoyo y difusión. La poca información que existe al respecto, no pasa de ser recetarios de cocina sin ningún contenido de investigación sociocultural e histórica que le de el derecho a su patente original, la cual sólo puede lograrse sobre la base de la investigación.

El presente trabajo pretende iniciar esta tarea de recopilación de la información existente desde las diferentes fuentes: los hallazgos y aportes de las investigaciones arqueológicas en la Amazonía peruana; los relatos de la documentación de la etnohistoria, de los primeros contactos con los europeos, la información de los primeros etnógrafos y las investigaciones antropológicas con los actuales grupos nativos de la cuenca del Ucayali.

La información de estas fuentes es muy diversa y no clasificada ni especifica, cosa que resulta un trabajo bastante tedioso para poder localizar, ordenar, clasificar y registrar de manera objetiva. Por otro lado el proyecto tiene como base de información, nuestros propios trabajos arqueológicos y etnográficos realizados desde el 2001 en la cuenca del Río Ucayali.

El proceso de investigación de las fuentes y el análisis de las evidencias arqueológicas disponibles nos permiten concluir que la comida loretana es el resultado de un largo proceso de adaptación al medio ambiente, la cual en sus orígenes fue muy sencilla, poco variada y muy sana en su contenido y que las actuales comidas loretana no son otra cosa que el resultado de un largo proceso de influencia andina-quechua, ocurrida con la época misional, junto al mestizaje de influencia occidental.

La investigación toma como base teórica el enfoque arqueológico que parte de los contextos domésticos asociados encontrados en los trabajos de prospecciones y excavaciones arqueológicas, sobre la base de ella contrasta la ley de la superposición estratigráfica, la asociación y la recurrencia de los artefactos, con el propósito de identificar al grupo social ó cultura, el espacio geográfico en el cual se desarrollo y determinar el tiempo cronológico de su existencia.

Sobre la base de la identificación espacio temporal del grupo social, se observan los patrones de conducta, expresados en determinados rasgos y elementos que se repiten en los tipos de artefactos, y así poder llegar a la primera interpretación, en referencia a la estrecha relación existente entre ciertas formas de artefactos de la cultura material y el consumo de determinados alimentos, en las culturas prehispánicas de la Amazonía peruana.

Un segundo acercamiento a la interpretación es en el ámbito de la etnoarqueologia, tomando como base las informaciones con relación a los alimentos o comidas, estos son contrastados con la información de las fuentes de la etnohistoria colonial y de los primeros años de la republica, además se utiliza 
la información en los actuales grupos nativos, para entender el proceso de evolución y cambios en la gastronomía loretana, desde la época prehispánica y el significado social que involucra los artefactos y los alimentos y de esta manera concluir, afirmando que existe un proceso originario de desarrollo de la gastronomía, que en la época colonial y republicana se produce un mestizaje que da origen a la exótica y variada gastronomía loretana.

El procedimiento desarrollado en la investigación consiste de dos etapas: la primera es un trabajo de gabinete y bibliotecas, con el objetivo de ubicar, recopilar y ordenar la información existente en las diferentes fuentes escritas como la arqueología, la etnohistoria y la antropología. Una segunda etapa, constituida por el trabajo de campo en el ámbito de prospección y excavaciones y el trabajo etnográfico en los actuales grupos nativos de la Cuenca del Ucayali.

\section{LA INFORMACIÓN ARQUEOLÓGICA}

La Amazonía peruana es un extenso territorio, en la cual aun no se dibuja la gran diversidad cultural prehispánica, apenas conocemos algunas características diferenciadas en sus estilos de cerámica; los contextos sociales excavados, son totalmente incompletos debido al tipo de ecosistema tropical muy humado y de alta temperatura, la cual ha destruido todos los restos de instrumentos u objetos de origen orgánico de aquellas poblaciones amazónicas que dejaron al final de su historia, dejando paso al frondoso bosque convertir los pueblos y ciudades en paisajes natura- les, donde hoy nadie podría imaginar que en el pasado hubo algunas huellas del hombre y que solo en las leyendas escritas han quedado como el país de las amazonas, la cual ha sido duramente cuestionada su existencia por los historiadores.

En este panorama arqueológico, es muy poco aún lo que los arqueólogos han aportado, sobre la alimentación o comidas prehispánicas en la amazonía; sin embargo en la arqueología andina, existen testimonios de los primeros productos alimenticios de origen amazónico, un ejemplo de ello son las representaciones de la planta de yuca, achira, maní y calabaza en la iconografía del llamado Obelisco Tello de la cultura Chavín que juntamente con el jaguar amazónico son los aportes amazónicos en el primer periodo del Horizonte temprano de las culturas andinas, con una antigüedad de más de 1,000 años a.C. (Morales 2002).

Pruebas arqueológicas del cultivo y uso de la yuca como alimento en la amazonía están inferidas sobre la base de los artefactos preservados para procesar la yuca, ente ellos los rayadores de yuca, cuyos dientes de lascas de piedra se han sido encontrados en excavaciones en el sito de Rancho Peludo, en el Nor.-Este de Venezuela según Rouse y Cruxent (1963), de igual manera existe información para la fase Momil I en Colombia, según R. Dolmatoff (1956), en la cuenca del Ucayali Central según Donald Lathrap esta evidencia aparece 1,000 años antes de Cristo en la fase llamada Hupa-iya, la cual es asociada a la tradición del estilo de cerámica 
llamada barrancoide de Venezuela y Colombia. Los rayadores de yuca son dientes de piedra que se incrustaban en una tabla, la cual servia para rayar la yuca para convertirla en harina para preparar panes de yuca y fariña, (ver Figura 1, ilustrado por Warren Deboer 1983:fig.4 a-g).
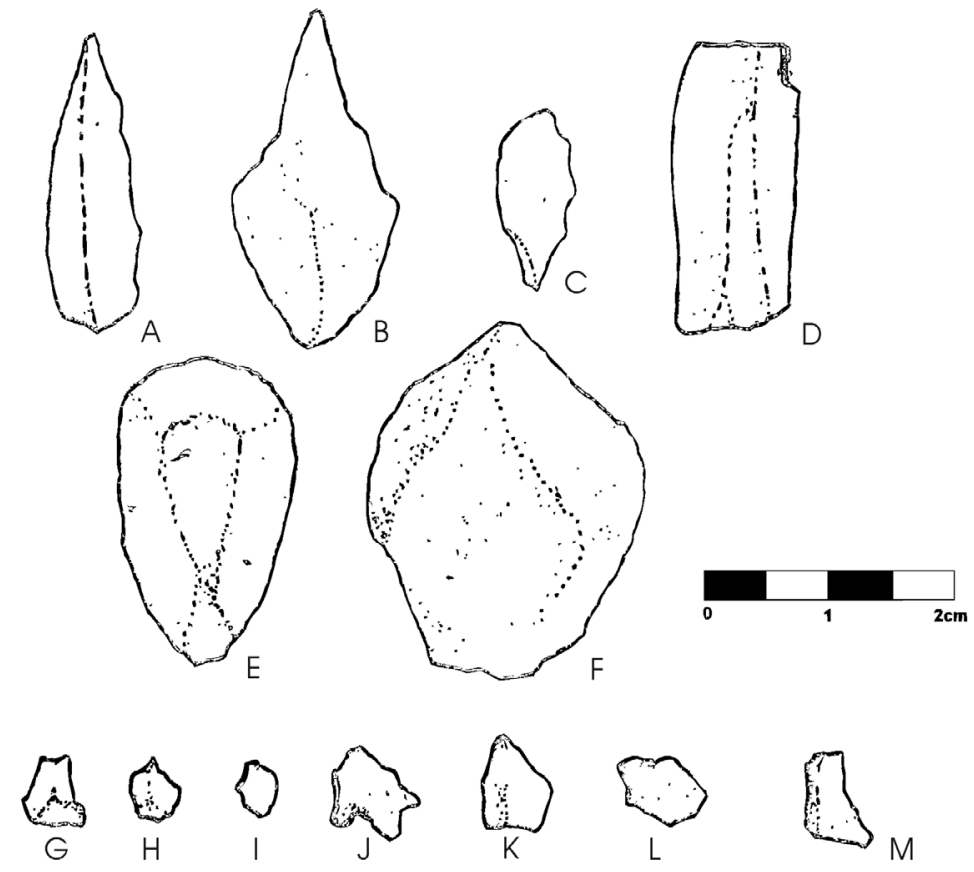

Figura 1 - 4 a-g: Tasquiles de Momil I (seleccionados de Reichel-Dolmatoff, 1856, Láminas XXVIII y XXiX); h-n: Dientes de piedra de los ralladores de yucca Waiwai, provenientes de la colección del Museu Americano de Historia Natural, Nueva York. La linea horizontal indica hasta qué profundidad es hundido el diente en la placa de Madera.

Otros artefactos que delatan la preparación de alimentos en la arqueo-logía amazónica son los llamados budares que son una especie de fuentes de cerámica que servían para tostar la yuca en el proceso de deshidratación de la harina de yuca para convertirlo en fariña; estos artefactos son de forma plana con el borde levantado y han sido ilustrados por Warren DeBoer (1983:fig.1 y 2) (Figura 2). Los budares y rayadores para procesar la yuca están muy ex- tendidos en las culturas prehispánicas de bosque tropical desde Venezuela y Colombia e inferidas para Perú y Brasil al igual que el uso de los "comales", que son platos similares a los budares pero de tamaño más pequeño y que sirven para preparar los panes o tortas de maíz.

Nuestras investigaciones arqueológicas en la cuenca baja de Ucayali y en las cuencas de los ríos Tigre, Chambira y Ucayali, han demostrado el uso de otros 


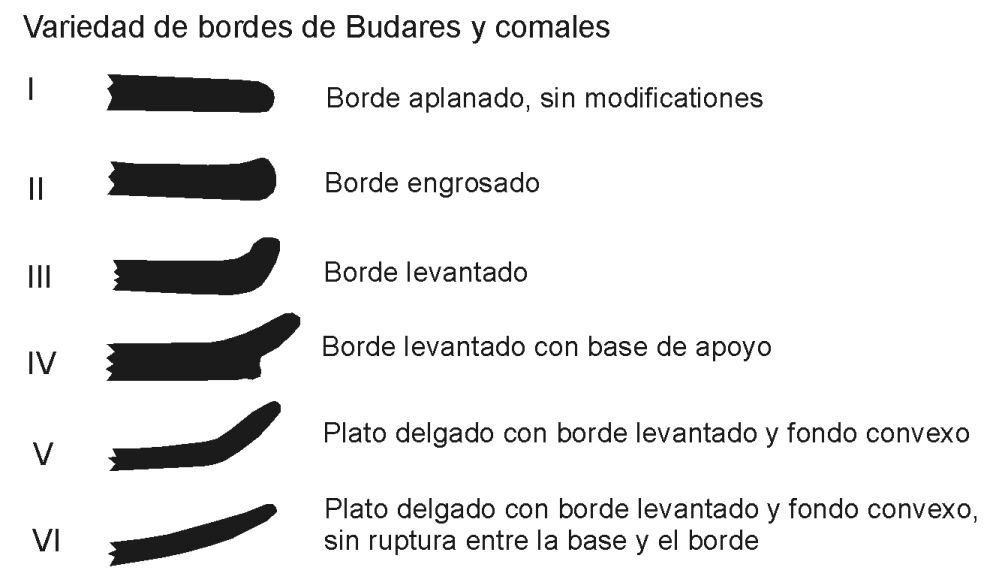

Frecuencia de bordes elevados y no modificados en platos de cerámica de Sudamérica y Mesoamérica

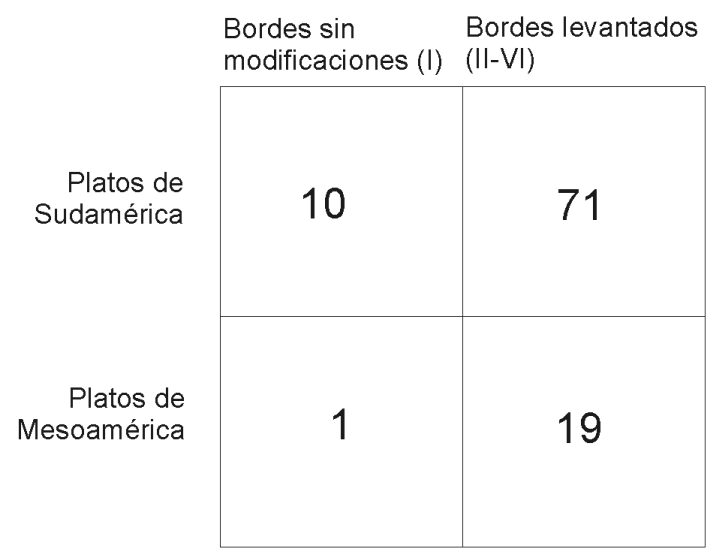

Figura 2 - Warren DeBoer (1983: fig.1 y 2)

Artefactos de cerámica que estarían vinculadas a la preparación del masato, que es la bebida fermentada de yuca; se trata de grandes cantaros llamados "masateras" donde se deposita la masa de yuca masticada para el masato. Así mismo identificamos algunas vasijas pequeñas muy decoradas y pintadas, a las cuales lo identificamos como "ceremoniales" y que luego posteriormente sobre la base de las las referencias etnográficas observadas en la cuenca del río Tigre la identificamos como "ayawasqueras", es decir ollas pequeñas muy alegóricas que sirven para depositar la ayahuasca que usan los chamanes para curar a la gente; de igual modo encontramos en la cuenca baja del Ucayali, en el sitio arqueológico del Zapotal otros artefactos pequeños de cerámica, los 
artefactos de cerámica que estarían vinculadas a la preparación del masato, que es la bebida fermentada de yuca; se trata de grandes cantaros llamados "masateras" donde se deposita la masa de yuca masticada para el masato. Así mismo identificamos algunas vasijas pequeñas muy decoradas y pintadas, a las cuales lo identificamos como "ceremoniales" y que luego posteriormente sobre la base de las las referencias etnográficas observadas en la cuenca del río Tigre la identificamos como "ayawasqueras", es decir ollas pequeñas muy alegóricas que sirven para depositar la ayahuasca que usan los chamanes para curar a la gente; de igual modo encontramos en la cuenca baja del Ucayali, en el sitio arqueológico del Zapotal otros artefactos pequeños de cerámica, los cuales fueron identificados por los nativos Shipibos como tostadores de maní, con una antigüedad entre los años 800 a 1,300 d.C.(ver Figura 3).

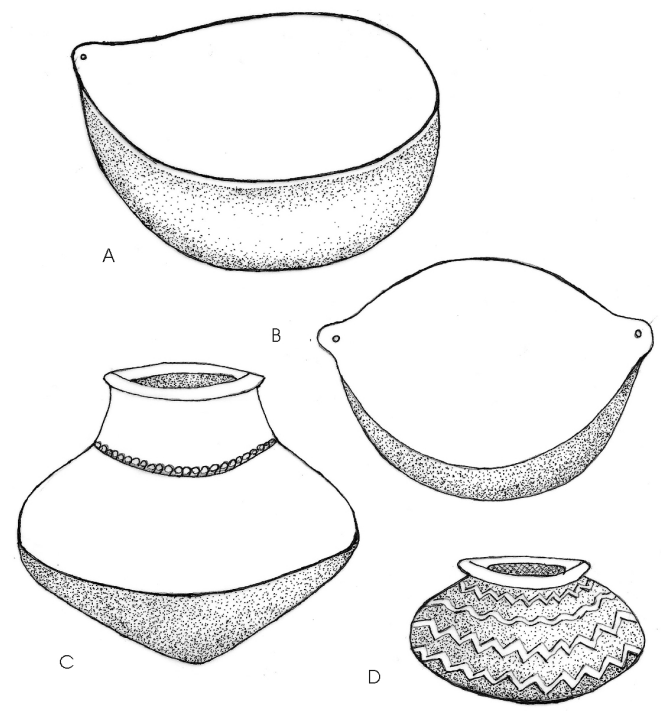

Figura 3 - A y B: tostadoras de mani; C:mazatera; D: ayahuasquera

Estas pruebas directas de la preparación de determinados alimentos sobre la base de la evidencia arqueológica son apenas el inicio de lo que la arqueología reporta de la preparación de alimentos como la fariña, el masato, los panes de yuca y de maíz, el maní tostado y la bebida sagrada de ayahuasca.

A lado de las pruebas directas de la preparación de alimentos sobre la base de la la evidencia de artefactos, también existen otros artefactos de cerámica correspondientes a la vajilla de la cocina; nosotros con el apoyo de la etnoarqueología hemos podido inferir el aspecto sociocultural o significado social de los actos de alimentación diaria en las culturas amazónicas, las cuales se relacionan al tamaño de las vasijas, las cuales han sido clasificadas en la tipología de formas hecha por el arqueó- 
logo Warren DeBoer en un trabajo de etnoarqueología de 1981. DeBoer en complemento al trabajo arqueológico reunió un censo de cerámica de cuatro asentamientos Conibo de la cuenca del Ucayali, clasificando las vasijas en tres tamaños: grades, medianos y pequeños y de acuerdo a la función, observo que en las vasijas para tomar el masato, las grandes se utilizan en fiestas, las medianas son de uso diario en la familia y las pequeñas se usan cuando se sale de viaje; en las ollas, las de mayor tamaño son para fermentar el masato, las medianas es de uso diario en la familia y las pequeñas para preparar medicamentos, lo mismo sucede en las tinajas: la grande para guardar masato, la mediana de uso común en el transporte de agua y la pequeña sirve como cantimplora para los viajes. Lo más importante en este trabajo de Warren, es que las mismas formas y tamaños se repiten para la cerámica arqueológica de los sitios de Shauaya y Sonochenia del alto Ucayali, con una antigüedad de 800 años d.C. (ver Figura 4, que ilustra los tamaños y formas de las vasijas tomadas de W. DeBoer 1981). Aunque las funciones no están bien interpretadas, nuestro proyecto etnográfico con los Sipibos-Conibos, observo que las vasijas grandes son de uso colectivo, especialmente en grandes fiestas como los casos de los ritos de pubertad, Conocida como la fiesta de "anishati", las medianas son de uso familiar y las pequeñas son de uso personal cuando sales de caza pesca o recolecta.

Pero lo más importante de esta información arqueológica, es que mediante estos tipos de artefactos y sus fun- ciones, según sus tamaños, es posible reconstruir aspectos de la vida social, donde la evidencia arqueológica con la información etnográfica nos ayuda comprender los modos de vida, que se repiten como tradición desde las culturas arqueológicas hasta los actuales grupos nativos. La observación nuestra de la vida diaria de los Shipibos del Ucayali y la participación con ello nos ha hecho entender que el consumo de alimentos diarios no es un acto individualizado, salvo cuando salen solos de caza o pesca al monte y se demoren varios días, las meriendas siempre son espacios de interacción donde se tratan muchos asuntos comunales. En la familia, la comida se sirve en grandes tazones, todos los hombres sentados en el suelo o sobre la tarima toman los alimentos con los dedos de un solo plato, otro grupo esta formado por mujeres y los hijos menores que de la misma forma toman sus alimentos de un gran tazón, igual sucede cuado se bebe masato en la familia, un gran cuenco de tamaño mediano es rotado por los hombres que van bebiendo el masato, es decir en estos casos se están usando vasijas medianas, mientras que las vasijas grandes son reservadas para las grandes fiestas como el "Anishati" la alimentación pasa a un segundo plano y el rito de pasaje es lo más importante dentro de la vida social, donde por cierto asisten muchos clanes de todas las cuencas y donde hay un gran derroche de comida y especialmente masato, que al final de la fiesta dejan en el piso una gran cantidad de vasijas rotas que son arrumadas a los rincones; según Steve King (1982), también entre los Angostero-Secoya del 
Norte de la Amazonía peruana, el consumo de alimentos es dentro de la familia extensa de un solo tazón, en ella también pueden participar otras familias a manera de intercambio y reciprocidad. Estas tres categorías de formas, como lo demuestra DeBoer, se dan también en vasijas para cocinar y depositar el agua, es decir ollas y cantaros; estas observaciones etnográficas de la cultura material en asociación a la vida social, nos indica también una división social por sexo y edad, relaciones sociales de amistad y unión al tomar el masato, es por eso cuando llegamos a una comunidad nativa, lo primero que te ofrecen es un tazón de masato, este acto no es tanto para satisfacer la sed que en el momento tal vez no la tienes, sino mas bien la señal de bienvenida y amistad que te ofrecen los nativos y que si tú no lo tomas, estas agrediendo o despreciando su amistad y bienvenida.

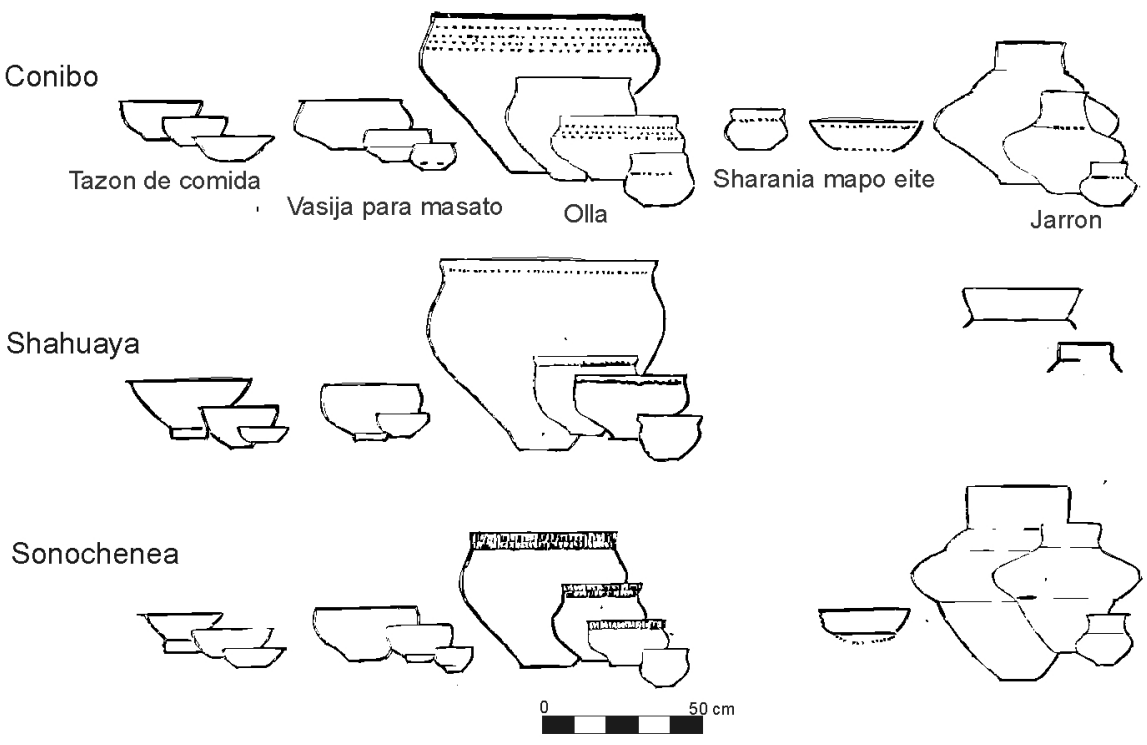

Figura 4 - Formas y tamaños de La alfareria Conibo (Etnografica) y Shohuaya y Sonochenia (Arqueologicas) que delatan funciones sociales categorizadas (DeBoer 1981)

\section{LA INFORMACIÓN \\ DE LA ETNOHISTORIA}

La información de las fuentes de la etnohistoria, escritas en los primeros momentos de los contactos en el año de 1542, cuando el capitán Don Francisco de Orellana descubre el gran Río Amazonas y observa grandes pueblos a ambas márgenes de este gran río, en donde Carvajal el cronista, expreso que estos pueblos eran tan grandes que temían ser atacados, y que el capitán no quiso tomar puerto alguno, y cuando ya no tenían provisiones, decidieron atacar al más pequeño y cuando entraron los soldados vieron tanta comida que expresaron que había tanta comida que podría durar para 1,000 hombres durante un año sin trabajar; se menciona la carne de monte hecha cecina, panes de yuca y maíz, pes- 
cado seco, aceite de manatí, mas de 7,000 tortugas en grandes corrales de charcos, frutas y otras cosas más.

Luego en los siglos XVII y XVIII e incluso el siglo XIX, especialmente los diarios de los misioneros nos hacen algunas referencias sobre los tipos de comidas, pero no muy variadas ni especifica, entre ellos vale la pena citar a Maroni quien en 1,738 nos dice: "Su sustento ordinario y como el pan cotidiano, es para unos la yuca y el plátano asado y cosido, para otros el maíz, que comen tostado o echo arepas que son unas tortas anchas y delgadas que tuestan en sartenes de barro a juego lento. Semejantes tortas fabrican con más frecuencia de mandioca o yuca brava y esto es lo que llaman vulgarmente casabe, de que gustan mucho los Omaguas, Yurimaguas y otras naciones, como también una especie de fariña, que sacan de la misma yuca. El modo más común de hacer si los casabes como la fariña, es este: ponen la yuca o mandioca con cáscara a podrir en el agua o a la orilla del río, haciéndole un cerco tapado con sus hojas y le dejan estar por un espacio de tres o cuatro días; el quinto día lo sacan y le quitan la cáscara, la muelen en un pilón; de allí en una bolsa que tejen de cierta cáscara, exprimen el sumo después la refriegan con la mano sobre el rallador, y floreada en un cernidor, la ponen en la tostadora y aplastándola primero con la mano, después con un mate, forman y tuestan al mismo tiempo los casabes. Del afrecho algo secado al sol y vuelto a tostar con una concha a que no se pege, sala la fariña que guardan al humo en una canastilla, se conserva muchos meses y años y sirve muchísimo en los caminos dilatados, supliendo la fal- ta de comida y bebida, pues no solo se hace con ella poleados o mazamorras de bastante sustento, sino que también se come de por si seca sin otro beneficio, y revuelto en agua fría la beben gustosos los indios"..."entre otros platos favoritos también comen gusanos y tienen por regalo varias que nosotros llamamos inmundicias, como sin lagartos del menos y culebras"... y cuando nos habla de los utensilios domésticos dice: "Toda sus alhajas domesticas se reducen a usar ollas, platos, tinajas para sus bebidas, mates o pilches, que son como dijimos una especie de calabazos que sirven de tazas para beber sus masatos".(Maroni, pp-176-177 y 178, en Noticias Autenticas del Famoso Río Marañón -1,738).

\section{LA INFORMACIÓN ETNOGRÁFICA}

A principios y mediados del siglo XX, los primeros etnógrafos, nos traen mayor información de los grupos nativos, en donde la información sobre la alimentación es muy suelta y sin comentarios, de ello podemos rescatar alguna información importante de Gunter Tessman (1,930), quien menciona el consumo de Palmito, masato de yuca, tabaco, en forma de cigarrillos, la coca era masticada, entre condimentos se usa la sal, y lo más común era la preparación de carne de monte ahumada, la cual se hacia sobre repisas en forma de mesas y al fuego lento con mucho humo.

Uno de los datos más importantes, resulta de la recopilación de cuentos y mitos de la selva de José Luis Jordana Laguna, publicada en Retablo de Papel, Edición INIDE 1974. De ella hemos tonado el mito de origen del Juego y los alimentos en los pueblos Aguaruna, 
esta leyenda dice: "Cuando los Aguarunas empezaron a poblar la selva del alto Marañón no conocían el juego, en aquel tiempo tampoco sabían cultivar la tierra, no tenían chacras y carecían de yuca y plátanos. Iwa el gigante que se alimentaba de gente era el único que poseía el juego y los alimentos, no se lo daba a los Aguarunas; pero un día "Jampue" el picaflor y "Yampits" la palomita se pusieron de acuerdo para robar el juego y los alimentos; decían, mientras yo agarro el juego tu "Yampits" aprovecho para conseguir toda clase de semillas que tiene "Iwa", para sembrar en las chacras, yo iré por acá y tu por alla. Así Jampue, remojo sus plumas en una quebrada y se echo a la trocha por donde pasaban las mujeres de Iwa, quienes al velo en el suelo tiritando de frío dijeron, i pobrecito picaflor!, ¡Esta muerto de frió!, vamos a llevarlo a la casa para que se caliente en el juego. Mientras tanto otra mujer de Iwa se encontró cerca de la casa a Yanpits la palomita que parecía que estaba muerta de hambre, la mujer la cogió y también la llevo a la casa para darle de comer semillas de frijoles, maíz y maní, la palomita trago todo y la guardo en el buche, mientras el picaflor que ya estaba bien seco, introdujo su larga cola al juego y se prendió sus plumas y luego levanto el vuelo, salió de la casa de Iwa y en el bosque quemo los árboles secos, así los Aguarunas pudieron recoger el juego y lo llevaron a sus casas y desde aquel entonces procuraron para que no se apague. Yampits, la palomita aprovechó que las mujeres de Iwa estaban preocupadas con la huida de Jempue, se escapo volando y llego a la casa de los Aguarunas y vomito las semillas de frijoles, maíz y maní y a partir de entonces empezaron a sembrar y cosechar sus alimentos".

Finalmente la información etnográfica con los actuales grupos nativos ShipiboConibo del Ucayali, nos reportan una riqueza mayor de potajes que son preparados en la selva, esto tal ves sea el producto de un mestizaje con los emigrantes andino-quechuas a la selva y la posterior influencia europea tarida por españoles y portugueses. De este modo en la amazonía peruana tenemos comidas exóticas como el Inchicapi, la sarapatera, canca de zuri, la fariña, el shibe, el inchicucho, el mingado, la patarashca, el pango, el tacacho, el upe, al aguajina, el chapo, y muchos otros platos los que han incrementado la riqueza gastronomía de la amazonía peruana. El arte culinario también a servido para expresar el sincretismo de las costumbres y tradiciones de los nativos, un caso importante es la creación de un potaje llamado "juanes" el cual es un tamal de arroz con una presa de gallina envuelta en hojas de bijao, cuyas puntas de las hojas son amarradas en la parte superior formando una simulación de cabeza trofeo; este plato es muy común en la fiesta de San Juan el 24 de Junio la más grande en toda la Amazonía, donde se dice que los juanes representan la cabeza decapitada de Juan el bautista, sincretizando en ella la costumbre nativa muy difundida de decapitar al enemigo y hacer con ella una cabeza trofeo.

\section{DISCUSIÓN}

La falta de evidencias o restos materiales del consumo de alimentos en las excavaciones arqueológicas en la amazonía, ha llevado a los arqueólogos al análisis artefactual, usando los criterios de 
superposición, asociación, recurrencia de los contextos y la morfología y función de los artefactos de cerámica para poder inferir la preparación y consumo de determinados alimentos y de las formas y tamaño de las vasijas, inferir los modos de vida colectiva, familiar e individual sobre el consumo de alimentos y sus implicancias sociales.

En la investigación sobre los alimentos, el estudio de la cultura material etnográfica, no es tan importante los objetos o artefactos o la propia comida como tales, sino más bien lo que mediante ella se puede entender a cerca de la vida social y sus creencias, no se trata de convertir esta investigación de los alimentos en un recetario culinario, pues los alimentos crean una cadena de relaciones sociales de amistad, parentesco, alianzas, paz y conflicto; de igual modo en el mundo ritual la comida tiene varios significados, los etnólogos destacan por ejemplo el canibalismo ritual, que consiste en comer la carne del jefe de la familia, con el objetivo de consolidar la unidad del clan o grupo social; en el cristianismo esta evoluciona en lo que se llama la instauración del santo sacramento donde se come el cuerpo y se toma la sangre de Cristo simbolizado en la ostia y el vino con el objetivo o compromiso de unidad en la fe cristiana (Tokareu 2003)

Así mismo el enfoque etno-arqueológico ha sido la herramienta fundamental en el proceso de investigación para reconstruir aspectos sociales muy importantes sobre la gastronomía prehispánica en la Amazonía peruana y el significado que envuelve el acto o ceremonia dentro de una sociedad, como es el caso del masato o los “juanes”.
Si bien hemos tratado sobre la alimentación o comidas nativas en la Amazonía, indudablemente el tema se vincula a la agricultura, el sedentarismo y el desarrollo de sociedades complejas, la cual han sido puestas al debate por Betty Meggers (1976), al afirmar que existe una relación entre el nivel de complejidad cultural alcanzado y el potencial agrícola de los suelos, los cuales en la Amazonía no son aptos para el desarrollo de la agricultura, por sus condiciones físico-químicas y el tipo de clima que no lo favorecen. Este debate fue llevado también al plano del consumo de recursos de proteínas en los pueblos amazónicos por R. Gross (1982), quien afirma que el tamaño, la permanencia y la densidad de los asentamientos aborígenes en la Amazonía están limitados a un bajo desarrollo debido a los recursos insuficientes de proteínas, consolidando de esta manera la propuesta de Meggers; sin embargo esta postura fue rebatida por Beckerman (1982), al sostener que el tamaño, permanencia y densidad de los asentamientos aborígenes en la Amazonía está sustentada en la abundancia de alimentación con alto índice de proteínas de origen animal y vegetal y que la causa del despoblamiento y dispersión actual han sido muchas epidemias que se dieron a partir del contacto con los europeos, así mismo en el pasado se demuestra que la presencia de tierras prietas de indios son los testimonios de grandes poblaciones prehistóricas.

De otro lado, Oliver (2008), propone una relación entre aparición de la cerámica con más de 6,000 años A.P. en el sitio 
de Taperina y la agricultura que se inicia después de un previo manejo de bosques y que esto a su vez según Raymond (2008), se relaciona al sedentarismo en sitios como Santa Elena en Ecuador, Cerro Mongote en Panamá y San Jacinto en Colombia con más de 4,000 años a.C.

Debemos considerar algunas limitaciones de la investigación al no considerar los estudios de etnobotánica y análisis de polen, los que están haciendo valiosos aportes para la zona de Colombia; así mismo el análisis de suelos o tierras prietas, que se hacen en los proyectos del Brasil, para detectar elementos químicos que delatan el consumo de determinados alimentos, tampoco hemos considerado los extensos campos de cultivo de los llanos de Mojos y las zonas de varzea en la cuenca amazónica, donde se sembraban diversos productos alimenticios, los cuales desconocemos cuales fueron en las épocas prehispánicas.

Es indudable que en la amazonía peruana existe una tradición originaria de comidas en base a productos muy propios del medio ambiente amazónico, los cuales incluso han trascendido desde épocas muy tempranas al área andina como lo demuestran reconocidos elementos iconográficos de la cultura Chavín; esta originalidad de consumo de determinados alimentos, al parecer se enriquece con la influencia tardía de los quechua hablantes que migraron a la Amazonía con los misioneros; esta influencia ha dejado en los nombres de las comidas una larga lista de palabras quechuas para designar a los potajes que incluso actualmente se consumen en la amazonía peruana.
Si bien es cierto que esta investigación tiene limitaciones, sin embargo es el primer esfuerzo por tratar de entender un aspecto tan importante de la vida del hombre prehispánico en la amazonía peruana, así mismo conocer la originalidad creativa de la gastronomía loretana.

\section{CONCLUSIONES}

1. La alimentación en las culturas prehispánicas de la Amazonía peruana, es el resultado de la adaptación de las sociedades a su medio ambiente.

2. La alimentación en sus orígenes fue poco variada, muy sencilla pero sana en su contenido alimenticio.

3. La información arqueológica mas antigua de preparación de alimentos data de los años 2,500 a.C., como prueba del consumo de yuca y sus derivados como la fariña y los panes; así mismo los artefactos de cerámica, por sus formas y función, delatan la preparación y consumo del masato, panes de maíz, maní tostado y el ayahuasca.

4. La referencia de las crónicas de 1542 afirman la existencia de diversos alimentos, en grandes cantidades y en grandes pueblos a las riveras del Amazonas, así mismo los misioneros hacen detalladas descripciones de lo que comían los nativos.

5. La información etnográfica actual de la gastronomía loretana, es más variada y diversa, como producto de los contactos con los andino-quechua-hablantes y el posterior mestizaje a partir del contacto con los europeos.

6. La comida loretana se enriquece día a día con nuevos potajes como los "juanes", que es un paquete de arroz con 
gallina, envuelto en hoja de bijao, la cual representa la cabeza de Juan el Bautista, sincretizando la cabeza trofeo tan común entre los Jibaros, Cocamas y Cocamillas.

\section{AGRADECIMIENTOS}

Agradezco la revisión y sugerencias, motivo por el cual hemos incluido dos párrafos en la discusión con la correspondiente bibliografía citada, reconociendo de antemano que el articulo no pretende agotar la discusión y la bibliografía.

\section{REFERENCIAS}

Beckeman, S. 1982. La abundancia de proteínas en la Amazonía: Una réplica a Gross. Amazonia Peruana III(6): 91-125.

Carbajal, G. de. 1894. Descubrimiento del Río Amazonas, según relación hasta ahora inédita de Fray Gaspar de Carbajal, con otros documentos a Francisco de Orellana sus compañeros. Con una introducción histórica e ilustración por osé Toribio Medina. Secilla: Imp. de E. Racso.

DeBoer, W. R. 1981. Longevidad cerámica e interpretación arqueológica: Un ejemplo del Alto Ucayali. Amazonía Peruana IV(7): 65-78.

1983. Pruebas arqueológicas del cultivo de yuca: Una nota de advertencia. Amazonía Peruana VI(8): 39-59.

Fordano, J.L. L. 1974. Mitos e Historia aguaruna y buambisha de la selva del Marañón en Retablos de Papel. Lima: INIDE.

Girard, R. 1958. Indios selvaticos de la Amazonía peruana. Ciudad de México: Libromex-Editores.

Gross, D. 1982a. Consumo proteínico y desarrollo cultural en la cuenca Amazónica. Amazonía Peruana III(6): 59-90.

1982b. Proteína y cultura en la Amazonía: Una segunda revisión. Amazonía Peruana III (6): 127-144.

Lathrap, D. 1970. The Upper Amazon. Ancient peoples and places. NewYork: Praeger.
Maroni, P. 1988 [1738]. Noticias autenticas del Río Marañón. Monumenta Amazónica. IIAP-CETALima: Universal.

Meggers, B. 1976. Amazonía: hombre y cultura en un paraíso ilusorio. México: Siglo XXI.

Morales, C. D.. 2000. Las Poblaciones Prehistóricas Amazónicas. Revista del Instituto de Investigaciones Histórico Sociales de la UNMSM IV(6) pp. 71-92. Lima-Perú.

2001. Aportes Amazónicos al Formativo Andino. Revista del Instituto de Investigaciones Histórico Sociales de la UNMSM V (8):35-64. Lima-Perú.

2002. Contactos entre Cocamas y Shipibos: Un acercamiento arqueológico en la Amazonía Peruana. Revista del instituto de Investigaciones Histórico Sociales de la UNMSM VI (10): 47-78. Lima-Perú.

Oliver, J.R. 2008. The archaeology of agriculture in ancient Amazonia, in Handbook of South American Archaeology. Editado por Heleaine Silverman y William H. Isbell, pp. 185-216. New York: Springer.

Raymond, S. J. 2008. The process of sedentism in northwestern South America, in Handbook of South American Archaeology. Editado por Heleaine Silverman y Willliam H. Isbell, pp. 79-92. New York: Springer.

King, S. y Alice Levey. 1982. Observaciones de la dieta de los Angostero-Secoya en el Norte del Perú. Amazonía Peruana III (6): 27-38.

Tessmann, G. 1999. Los indios del Perú Nororiental. Investigaciones, Fundamentos para un estudio sistemático de la cultura. Quito: Ediciones Abya-Yala. Primera edición completa en español.

Tokareu, S. 2003. Contribución al Método para el estudio etnográfico del la cultura material. In: Temas Antropológicos, de Jorge Mariano Cáceres Olazo Monroy. Universidad Federico Villarreal. 